\title{
Direct Characterization of Bitter Acids in a Crude Hop Extract by Liquid Chromatography-Atmospheric Pressure Chemical Ionization Mass Spectrometry
}

\author{
Xiaozhe Zhang, Xinmiao Liang, Hongbin Xiao, and Qing Xu \\ Dalian Institute of Chemical Physics, Chinese Academy of Sciences, Dalian, China
}

\begin{abstract}
The applicability of on-line coupling of reversed-phase high-performance liquid chromatography to atmospheric pressure ionization tandem mass spectrometry for the separation and characterization of hop acids mixture from the crude extract of Humulus lupulus was investigated. The solvent system consisting of acetonitrile-aqueous formic acid was used to give proper separation of the six main hop bitter acids within 30 min. Further structural information about the components was acquired by collision-induced dissociation (CID). On the basis of analyses of the fragmentation patterns of the major $\alpha$ - and $\beta$-bitter acids respectively, identification of the minor ones was performed using selected reaction monitoring (SRM) with a group of qualitatively relevant selected precursor-product ion transitions for each bitter acid in a single high performance liquid chromatography (HPLC) run. Using this technique, six minor hop acids, including "adprelupulone" observed for the first time in natural resources, were detected along with the six major acids. This hyphenated techniques provides potency for rapid qualitative determination of analogs and homologs in mixtures. (J Am Soc Mass Spectrom 2004, 15, 180-187) () 2004 American Society for Mass Spectrometry
\end{abstract}

$\mathrm{T}$ The hop plant (Humulus lupulus L., Cannabaceae) is widely cultivated in the world for its female inflorescence (commonly referred to as "hop cones" or "hops"). The bitter, resinous substance produced in the glandular hairs of the strobiles is used in brewing for adding aroma and flavor to beer. Hops also have a long history in folkloric medicine for the bacteriostatic action and preservative qualities. Phytoestrogen and anticancer activities of bitter acids have been reported in recent years.

The hop bitter acids are resinous alicyclic phenolic acids and usually classified as $\alpha$-acids and $\beta$-acids. They present in hops as a complex mixture of varying composition and concentrations. The main $\alpha$-acids are humulone, cohumulone, and adhumulone; the corresponding $\beta$-acids are lupulone, colupuone, and adlupulone (see Figure 1). Besides the two series of normal-, co-, and ad-homologs, there exist some minor hop acids in the plant, including posthumulone/postlupulone, prehumulone/prelupulone and adprehumulone [1]. They are several homologs and analogs, and the $\beta$-acids differ structurally from the $\alpha$-acids by having one more prenyl group.

Published online December 9, 2003

Address reprint requests to Dr X. Liang, Group of Pharmaceutical Chemistry, Dalian Institute of Chemical Physics, Chinese Academy of Sciences, 161 Zhongshan Road, Dalian 116011, China. E-mail: zhangxz@sina.com.cn
HPLC with UV detection is routinely used to analyze bitter acids [2-9]. The sensitivity and selectivity of UV are insufficient for direct identification of hop acids, especially for the identification of minor hop acids in complex mixtures. The instability and structural similarity of the hop bitter acids cause difficulty in routine analyses. So the application of on-line coupling of high-performance liquid chromatography to mass spectrometry is an attractive option to separate and identify such components.

Recently, the detection of these compounds by HPLC coupled to mass spectrometry was investigated. Van der Hoeven et al. [10] reported on (negative) LC/ESI/ MS/MS application to the analysis of the six major bitter acids in the extract of hop. In the ESI experiment, MS/MS spectra of $\beta$-acids exhibit abundant product ions corresponding to loss of a series of alkyl radicals. For $\alpha$-acids, the MS/MS spectra showed mainly one product ion corresponding to loss of the $69\left(\mathrm{C}_{5} \mathrm{H}_{9}\right)$ side chain. Under (negative) ESI conditions, all the fragmentation occurred on the prenyl groups and no product ion corresponding to loss of acyl group was observed. It was not sufficient to specify the structural difference of the homologs and analogs.

Most of these analyses by HPLC focus on the separation and detection of the six major hop acids. Identification of the major hop acids may be relatively easy solely by their UV absorbance wavelength and chro- 
<smiles>[R]C(=O)C1=C(O)C(CC=C(C)C)=C(O)C(O)(CC=C(C)C)C1=O</smiles>

a-acids (humulones)

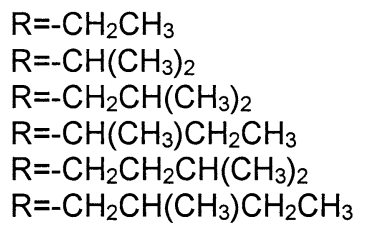<smiles>[R]C(=O)C1=C(O)C(CC=C(C)C)=C(O)C(CC=C(C)C)(CC=C(C)C)C1=O</smiles>

$\beta$-acids (lupulones)

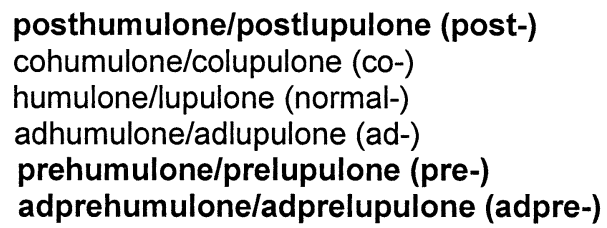

Figure 1. Chemical structures of hop bitter acids as discussed in the text.

matographic retention rule. Molecular weights and some fragment ions obtained in the MS experiment can confirm the results. For the minor hop acids it remains difficult to detect all of them in the crude hop extract by multiple LC-MS experiments because of unavailable commercial standards. However, it may be possible to determine such trace bitter acids by using SRM when the fragmentation patterns of the major hop acids have been obtained. The high sensitivity and selectivity of SRM allow determining the minor hop acids rapidly, particularly to eliminate interferences from other compounds when multiple precursor-product ion transitions for one hop acid were monitored.

In the present study we developed an isocratic separation method using acetonitrile-aqueous formic acid elution system, which can be directly subjected to MS spectrometry and supply definitive separation capability for the six main hop bitter acids within $30 \mathrm{~min}$. Specific structural information was acquired with CID and structural differences were elucidated by the fragment ions. The minor bitter acids were detected by SRM scanned with a group of pair ion transitions in one HPLC run for each hop acid, based on the analyses of the six major hop bitter acids by HPLC coupled with atmospheric pressure ionization tandem mass spectrometry (APCI-MS-MS).

\section{Materials and Methods}

\section{Reagents and Standards}

HPLC grade acetonitrile (Tedia, Fairfield, OH) was used for HPLC analysis. Water for HPLC mobile phase was purified with a Milli-Q system (Millipore, Bedford, MA). Formic acid was obtained from Acros (Fair Lawn, $\mathrm{NJ}$ ), Reagent grade acetone and ethanol (Lianbang Chemical Co., Shenyang, China) were used for extraction and separation. The authentic standard, colupulone, was homemade by recrystallization.

\section{LC-MS Method}

For HPLC separations a Waters 2690 system (Waters, Milford, MA) equipped with an automatic sample injector was used. All separations were performed with an Inersil ODS3 column $(5 \mu \mathrm{m}, 4.6 \times 250 \mathrm{~mm}$, i.d., GM, GL Sciences, Tokyo, Japan), eluted at $0.8 \mathrm{~mL} / \mathrm{min}$ with acetonitrile- $8 \%$ formic acid 85:15 for $30 \mathrm{~min}$. LC/UV traces were recorded on-line with a Waters 2690 PDA detector with detection at $330 \mathrm{~nm}$. The ethanol extract of Humulus lupulus was filtered through a $0.45 \mu \mathrm{m}$ syringe filter and injected $(10 \mu \mathrm{L})$ onto the column.

MS experiments were performed on a triple-quadrupole mass spectrometer (TSQ, Finnigan MAT, San Jose, CA) equipped with an APCI interface. The heated capillary temperature was set at $200^{\circ} \mathrm{C}$, vaporizer temperature at $400{ }^{\circ} \mathrm{C}$, auxiliary gas at 10 arbitrary units, sheath gas at 40 psi. For MS/MS, Argon (Ar) was used as target gas ( 3 mTorr) in the collision. The corona discharge voltage was set at $4 \mathrm{kV}$, the corona discharge current at $4 \mu \mathrm{A}$. The precursor isolation window was set $1 \mathrm{u}$ and the collision energy was set at $20 \sim 30 \mathrm{~V}$.

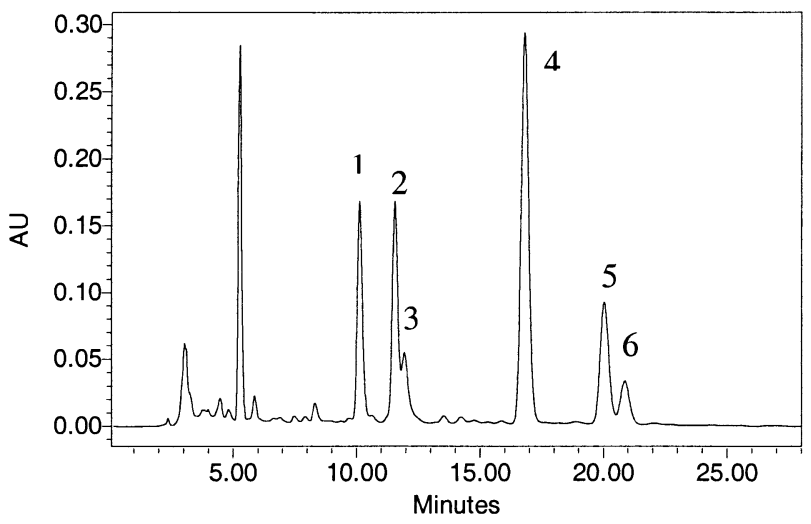

Figure 2. HPLC chromatogram of hop acids from a crude extract of Humulus lupulus L. 

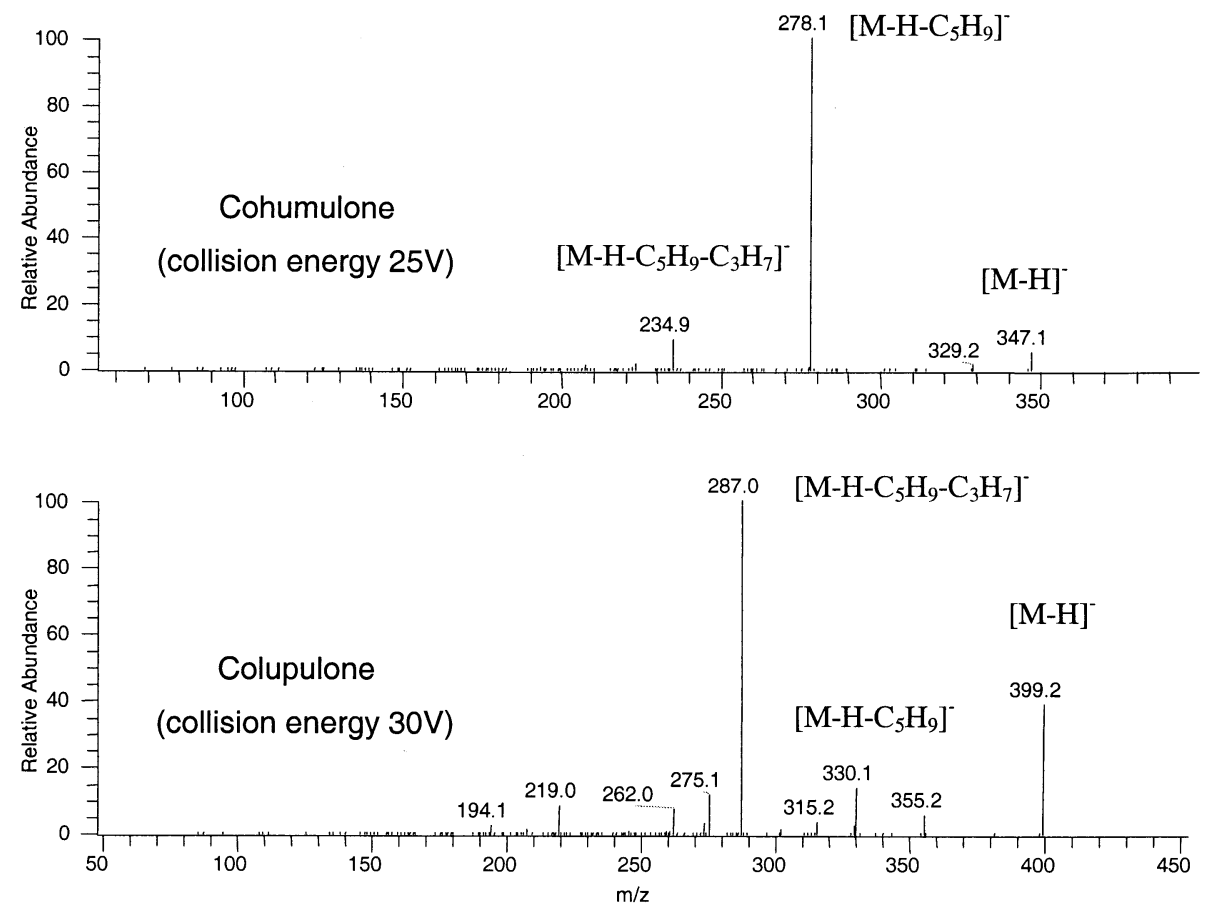

Figure 3. (Negative) APCI-MS/MS spectrum of cohumulone and colupulone.

Initially, the mass spectrometer was programmed to perform full scans between 100 and $500 \mathrm{~m} / \mathrm{z}$ in order to observe molecular ion signals as well as fragments or adducts in positive/negative ion mode. Secondly, in MS/MS mode CID of positive molecular ions recorded in MS was carried out to determine the components respectively.

\section{Plant Material and Sample Preparation}

Humulus lupulus was purchased from Xinjiang, China. The substance $(5 \mathrm{~g})$ underwent ultrasonic extraction three times for $30 \mathrm{~min}$ each time with $40 \mathrm{~mL}$ ethanol. The extract was combined and concentrated to $100 \mathrm{~mL}$ for LC-MS analysis.

\section{Results and Discussion}

\section{Chromatography}

The separation of hop acids is strongly dependent on the concentration of acetonitrile in the eluent. Complete separation between adhumulone and humulone was performed at acetonitrile-water ratio $\leq 65: 35$, while the ratio for the separation of lupulone and adlupulone was $75: 25$ or less. A gradient elution profile using acetonitrile and $8 \%$ formic acid could be a solution to the problem of baseline separation of normal- and adcompounds, but there was no aid yielded by MS analysis in the distinction between the normal- and ad-isomers because of their identical MS/MS spectra. For the rapid screening of bitter acids, an isocratic elution system was employed using high acetonitrilewater ratio $(85: 15)$ to finish HPLC within $30 \mathrm{~min}$.

\section{LC/APCI-MS/MS Detection of the Six Major Hop} Acids

LC-APCI-MS experiments were initially performed on the major bitter acids of Humulus lupulus L. using a triple-quadrupole mass spectrometer. All of the six main hop acids can generate predominantly protonated

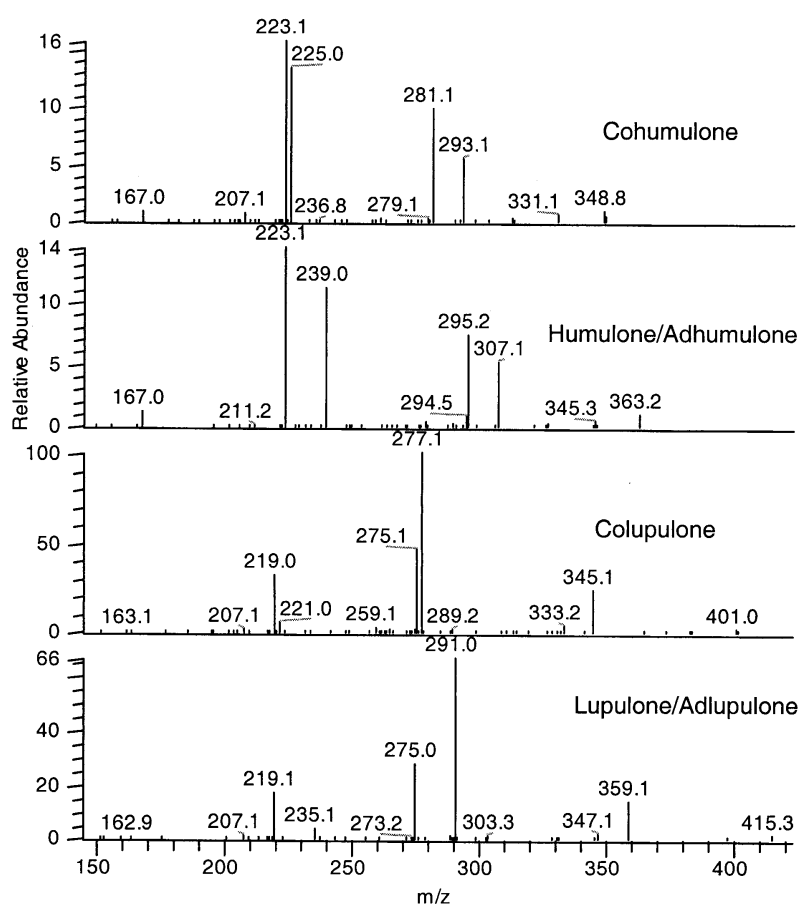

Figure 4. (Positive) APCI-MS/MS spectrum of six major hop acids. 
Table 1. Specific structure information of $\alpha$-acids from LC-APCI-MS/MS

\begin{tabular}{|c|c|c|c|c|c|c|}
\hline \multirow[b]{2}{*}{$\begin{array}{l}\text { lon } \\
\text { number } \\
\text { (n) }\end{array}$} & \multirow{2}{*}{$\begin{array}{l}\text { Precursor ion- } \\
\text { product ion } \\
\text { transition } \\
\left(A_{0} \rightarrow A_{n}\right)\end{array}$} & \multirow[b]{2}{*}{ MS/MS assignment } & \multicolumn{2}{|c|}{ Observed } & \multicolumn{2}{|c|}{ Predicted } \\
\hline & & & $\begin{array}{l}\text { Humulone/ } \\
\text { admumulone } \\
\text { (intensity) }\end{array}$ & $\begin{array}{c}\text { Cohumulone } \\
\text { (intensity) }\end{array}$ & Posthumulone* & $\begin{array}{l}\text { Prehumulone*/ } \\
\text { adprehumulone* }\end{array}$ \\
\hline$A_{0}$ & I & {$[\mathrm{M}+\mathrm{H}]^{+}$} & 363 & 349 & 335 & 377 \\
\hline$A_{1}$ & $A_{0} \rightarrow A_{1}$ & {$\left[\mathrm{M}+\mathrm{H}-\mathrm{H}_{2} \mathrm{O}\right]^{+}$} & $345(2)$ & $331(3)$ & 317 & 359 \\
\hline$A_{2}$ & $A_{0} \rightarrow A_{2}$ & {$\left[\mathrm{M}+\mathrm{H}-\mathrm{C}_{4} \mathrm{H}_{8}\right]^{+}$} & $307(35)$ & $293(35)$ & 279 & 321 \\
\hline$A_{3}$ & $A_{0} \rightarrow A_{3}$ & {$\left[\mathrm{M}+\mathrm{H}-\mathrm{C}_{5} \mathrm{H}_{8}\right]^{+}$} & $295(51)$ & $281(63)$ & 267 & 309 \\
\hline A4 & $A_{0} \rightarrow A_{4}$ & {$\left[\mathrm{M}+\mathrm{H}-\mathrm{C}_{5} \mathrm{H}_{8}-\mathrm{C}_{4} \mathrm{H}_{8}\right]^{+}$} & $239(78)$ & $225(85)$ & 211 & 253 \\
\hline$A_{5}$ & $A_{0} \rightarrow A_{5}$ & {$\left[\mathrm{M}-\mathrm{C}_{4} \mathrm{H}_{8} \text {-Alkene-CO }\right]^{+}$} & $223(100)$ & $223(100)$ & 223 & 223 \\
\hline$A_{6}$ & $A_{0} \rightarrow A_{6}$ & {$\left[\mathrm{M}-2 \mathrm{C}_{4} \mathrm{H}_{8} \text {-Alkene-CO }\right]^{+}$} & $167(8)$ & $167(6)$ & 167 & 167 \\
\hline
\end{tabular}

Alkene: Formed by neutral loss of alkyl side-chain on acyl group.

* The product ions of which are predicted on the basis of fragmentation pattern of its homologues.

molecular ions in positive ion mode (or deprotonated molecular ions in negative ion mode). Thus, it is easy to distinguish these compounds from the LC-MS chromatogram by their molecular weights and chromatographic retention rule [4]. The elution sequence of the homologs is co-, normal-, and ad-hop acids in an LC/UV run with the elution system used (see Figure 2).

Hop acids can be analyzed in positive as well as in negative mode but the sensitivity is slightly less in positive ion mode than in negative ion mode considering their phenolic structures. Under (nagative) APCI conditions, the fragmentation of precursor ions occurred mainly on the prenyl groups as observed in negative ESI-MS/MS experiment [10] and no abundant product ion corresponding to the loss of acyl group was formed (see Figure 3). Under (positive) APCI conditions, fragmentation of protonated ions could present more characteristic product ions than fragmentation of deprotonated molecular ions (see Figure 4). Hence, structural identification of bitter acids was performed in positive ion mode for the purpose of qualitative analysis.

In addition to predominantly protonated molecular ions, some characteristic fragment ions with relatively low intensity were observed under APCI-MS conditions as mentioned above. Such fragments were thermally generated and depended mainly on the capillary temperature. When the heated capillary temperature was set at $200^{\circ} \mathrm{C}$, MS spectra of colupulone and lupulone both presented intensive protonated molecular ions with fragment ions at $m / z 275$. CID of the fragment ion for each compound showed almost identical product ions. The presence of the ion at $m / z 275$ indicated that the fragment was formed after the acyl group, which was the main difference between the two homologs, was entirely lost. The deduction was supported by the following MS/MS experiments.

Under the MS/MS condition, abundant product ions were obtained from the protonated molecular ions of $\alpha$ and $\beta$-acids. For colupulone, MS/MS spectrum presented major peaks at $m / z 345,333,277,275,221,219$, and 163. An $[\mathrm{M}-56]^{+}$peak at $m / z 345$ corresponded to the cleavage of a prenyl group, and an $[\mathrm{M}-68]^{+}$peak at $m / z 333$ showed the removal of a prenyl group. The ion at $m / z 277$ formed by a consecutive loss of $56\left(\mathrm{C}_{4} \mathrm{H}_{8}\right)$ and $68\left(\mathrm{C}_{5} \mathrm{H}_{8}\right)$, while a peak at $m / z 275$ could be attributed to the ion formed after entire loss of the alkyl side-chain of acyl plus a loss of $56\left(\mathrm{C}_{4} \mathrm{H}_{8}\right)$. The characteristic fragments indicated the multi-prenyl substituted structure of colupulone.

Table 2. Specific structure information of $\beta$-acids from LC-APCI-MS/MS

\begin{tabular}{|c|c|c|c|c|c|c|}
\hline \multirow[b]{2}{*}{$\begin{array}{l}\text { Ion } \\
\text { number } \\
\text { (Bn) }\end{array}$} & \multirow{2}{*}{$\begin{array}{l}\text { Precursor ion- } \\
\text { product ion } \\
\text { transition } \\
\left(\mathrm{B}_{0} \rightarrow \mathrm{B}_{\mathrm{n}}\right) \\
\end{array}$} & \multirow[b]{2}{*}{ MS/MS assignment } & \multicolumn{2}{|c|}{ Observed } & \multicolumn{2}{|c|}{ Predicted } \\
\hline & & & $\begin{array}{l}\text { Lupulon/ } \\
\text { adlupulone } \\
\text { (intensity) }\end{array}$ & $\begin{array}{c}\text { Colupulone } \\
\text { (intensity) }\end{array}$ & Postlopulone* & $\begin{array}{l}\text { Prelupulone*/ } \\
\text { adprelupulone* }\end{array}$ \\
\hline $\mathrm{B}_{0}$ & I & {$[\mathrm{M}+\mathrm{H}]^{+}$} & 415 & 401 & 387 & 429 \\
\hline $\mathrm{B}_{1}$ & $\mathrm{~B}_{0} \rightarrow \mathrm{B}_{1}$ & {$\left[\mathrm{M}+\mathrm{H}-\mathrm{C}_{4} \mathrm{H}_{8}\right]^{+}$} & $359(20)$ & $345(23)$ & 331 & 373 \\
\hline $\mathrm{B}_{2}$ & $\mathrm{~B}_{0} \rightarrow \mathrm{B}_{2}$ & {$\left[\mathrm{M}+\mathrm{H}-\mathrm{C}_{5} \mathrm{H}_{8}\right]^{+}$} & $347(2)$ & $333(4)$ & 319 & 361 \\
\hline $\mathrm{B}_{3}$ & $\mathrm{~B}_{0} \rightarrow \mathrm{B}_{3}$ & {$\left[\mathrm{M}+\mathrm{H}-\mathrm{C}_{5} \mathrm{H}_{8}-\mathrm{C}_{4} \mathrm{H}_{8}\right]^{+}$} & $291(100)$ & $277(100)$ & 263 & 305 \\
\hline $\mathrm{B}_{4}$ & $\mathrm{~B}_{0} \rightarrow \mathrm{B}_{4}$ & {$\left[\mathrm{M}+\mathrm{H}-\mathrm{C}_{5} \mathrm{H}_{8}-2 \mathrm{C}_{4} \mathrm{H}_{8}\right]^{+}$} & $235(5)$ & $221(5)$ & 207 & 249 \\
\hline$B_{5}$ & $\mathrm{~B}_{0} \rightarrow \mathrm{B}_{5}$ & {$\left[\mathrm{M}+\mathrm{H}-\mathrm{C}_{4} \mathrm{H}_{8} \text {-Alkene-CO }\right]^{+}$} & $275(41)$ & $275(46)$ & 275 & 275 \\
\hline B6 & $\mathrm{B}_{0} \rightarrow \mathrm{B}_{6}$ & {$\left[\mathrm{M}+\mathrm{H}-2 \mathrm{C}_{4} \mathrm{H}_{8} \text {-Alkene-CO }\right]^{+}$} & $219(26)$ & $219(32)$ & 219 & 219 \\
\hline $\mathrm{B}_{7}$ & $\mathrm{~B}_{0} \rightarrow \mathrm{B}_{7}$ & {$\left[\mathrm{M}+\mathrm{H}-3 \mathrm{C}_{4} \mathrm{H}_{8} \text {-Alkene-CO }\right]^{+}$} & $163(1)$ & $163(1)$ & 163 & 163 \\
\hline
\end{tabular}

Alkene: Formed by neutral loss of alkyl side-chain on acyl group.

*The product ions of which are predicted on the basis of fragmentation pattern of its homologues. 


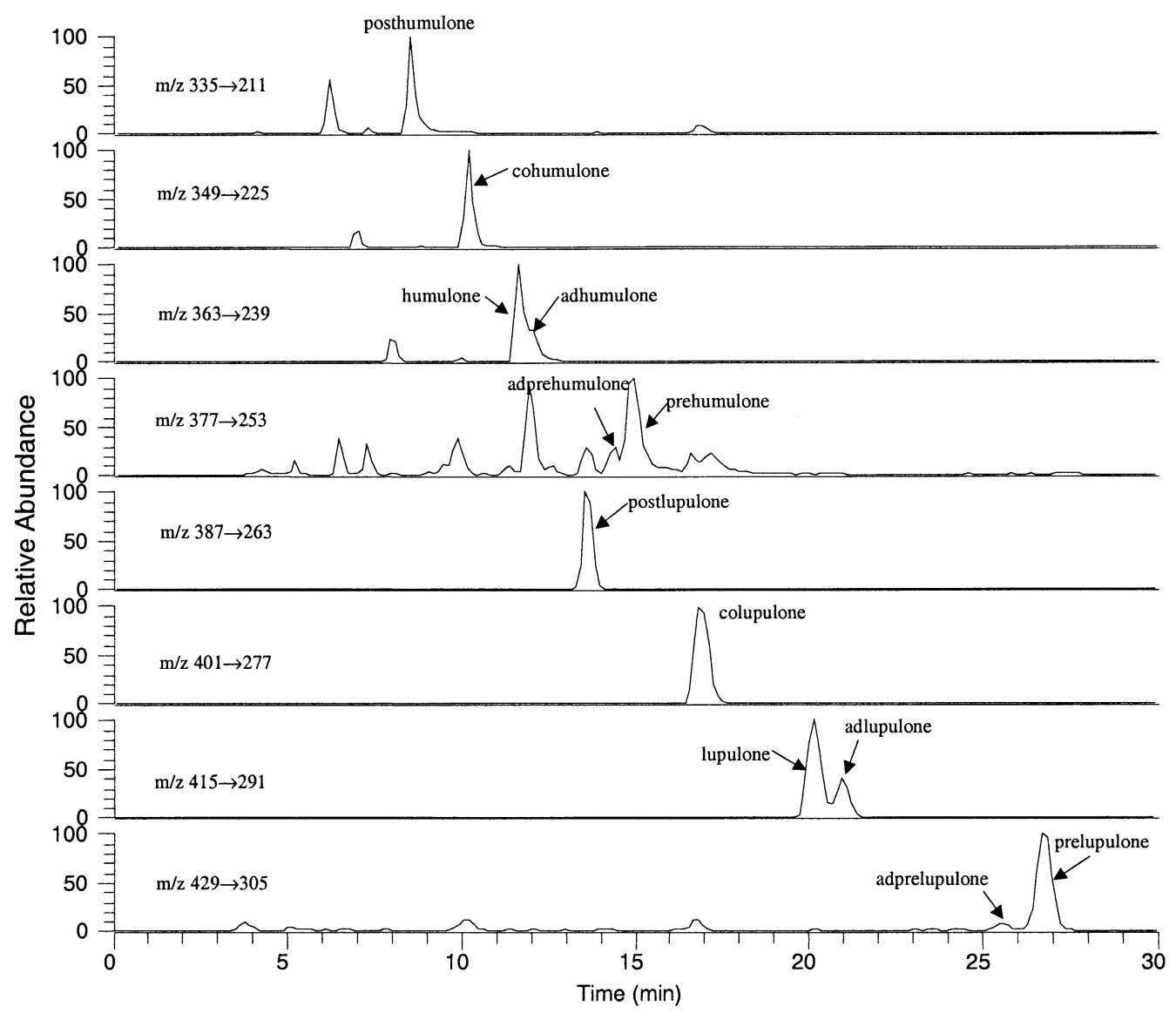

Figure 5. SRM-LC-MS/MS chromatograms of hop bitter acids from the crude extract.

The MS/MS spectrum of lupulone presents major peaks at $\mathrm{m} / \mathrm{z} 359,347,291,275,235,219$, and 163 corresponding to the characteristic losses of $56\left(-\mathrm{C}_{4} \mathrm{H}_{8}\right)$, $68\left(-\mathrm{C}_{5} \mathrm{H}_{8}\right), 124\left(-\mathrm{C}_{5} \mathrm{H}_{8},-\mathrm{C}_{4} \mathrm{H}_{8}\right), 140\left(-\mathrm{CO},-2 \mathrm{C}_{4} \mathrm{H}_{8}\right), 180(-\mathrm{CO}$, $\left.-2 \mathrm{C}_{4} \mathrm{H}_{8},-\mathrm{C}_{5} \mathrm{H}_{8}\right), 196\left(-\mathrm{CO},-3 \mathrm{C}_{4} \mathrm{H}_{8}\right)$, and $252\left(-\mathrm{CO},-4 \mathrm{C}_{4} \mathrm{H}_{8}\right)$, respectively. Comparison with the MS/MS spectra of colupulone and lupulone showed that the two homologs readily follow the identical fragmentation rule. Lupulone differs structurally from colupulone by having one more methylene group. Therefore, it formed product ions with $\mathrm{m} / \mathrm{z} 14$ more than the corresponding product ions for colupulone; whereas the product ions at the same $\mathrm{m} / \mathrm{z}$ for both bitter acids could be attributed to the consequent fragments formed after entire the loss of the acyl group (see Table 2).

In comparison with $\beta$-acids, $\alpha$-acids are the relatively favored form of the $\left[\mathrm{M}+\mathrm{H}-\mathrm{H}_{2} \mathrm{O}\right]^{+}$ions. In addition, protonated molecular ions of the three major $\alpha$-acids fragmented to give the same ion at $\mathrm{m} / \mathrm{z} 167$ corresponding to $\left[\mathrm{M}+\mathrm{H}-\mathrm{CO}-\text { Alkene- } 2 \mathrm{C}_{4} \mathrm{H}_{8}\right]^{+}$, which showed diprenyl substituted structures of these bitter acids. Thus the structural difference between $\alpha$ - and $\beta$-acids was ultimately revealed by CID performed in positive ion mode. Proposed fragmentation pathway of cohumulone and colupulone are presented (see Schemes 1 and 2).
The ad- and normal-isomers cannot be directly discriminated by MS/MS analysis because of similar fragmentation patterns of the homologs. The fragmentation of major $\alpha$ - and $\beta$-hop acids present regular fragmentation pathway respectively. Therefore, it was expected that protonated ions of the other six minor hop acids would give product ions following the fragmentation route of their homologs in MS/MS (predicted product ions of minor hop acids are listed in Tables 1 and 2). The SRM-LC-MS/MS analyses that followed were conducted with specific parent ions for major hop acids; for minor acids, data-dependent scans were done on the basis of MS-MS results obtained above.

\section{Detection of the Minor Hop Acids}

For colupulone the most intense ion at $\mathrm{m} / \mathrm{z} 277$ in the full-scan product ion spectrum was chosen for monitoring in SRM mode. The detection limit using the pair ion $\mathrm{m} / \mathrm{z} 401 \rightarrow 277$ detected could be as low as $0.04 \mathrm{ng} / \mathrm{mL}$ (signal-to-noise ratio $=3$ ).

Postlupulone, reported existing in hop, was the first one selected to analyze by using SRM. As shown in Table 2, CID of protonated ion at $\mathrm{m} / \mathrm{z} 387$ for postlupulone possibly produces characteristic ions at $\mathrm{m} / \mathrm{z} 331$, $319,263,207,275,219$, and 163 corresponding to [M + 


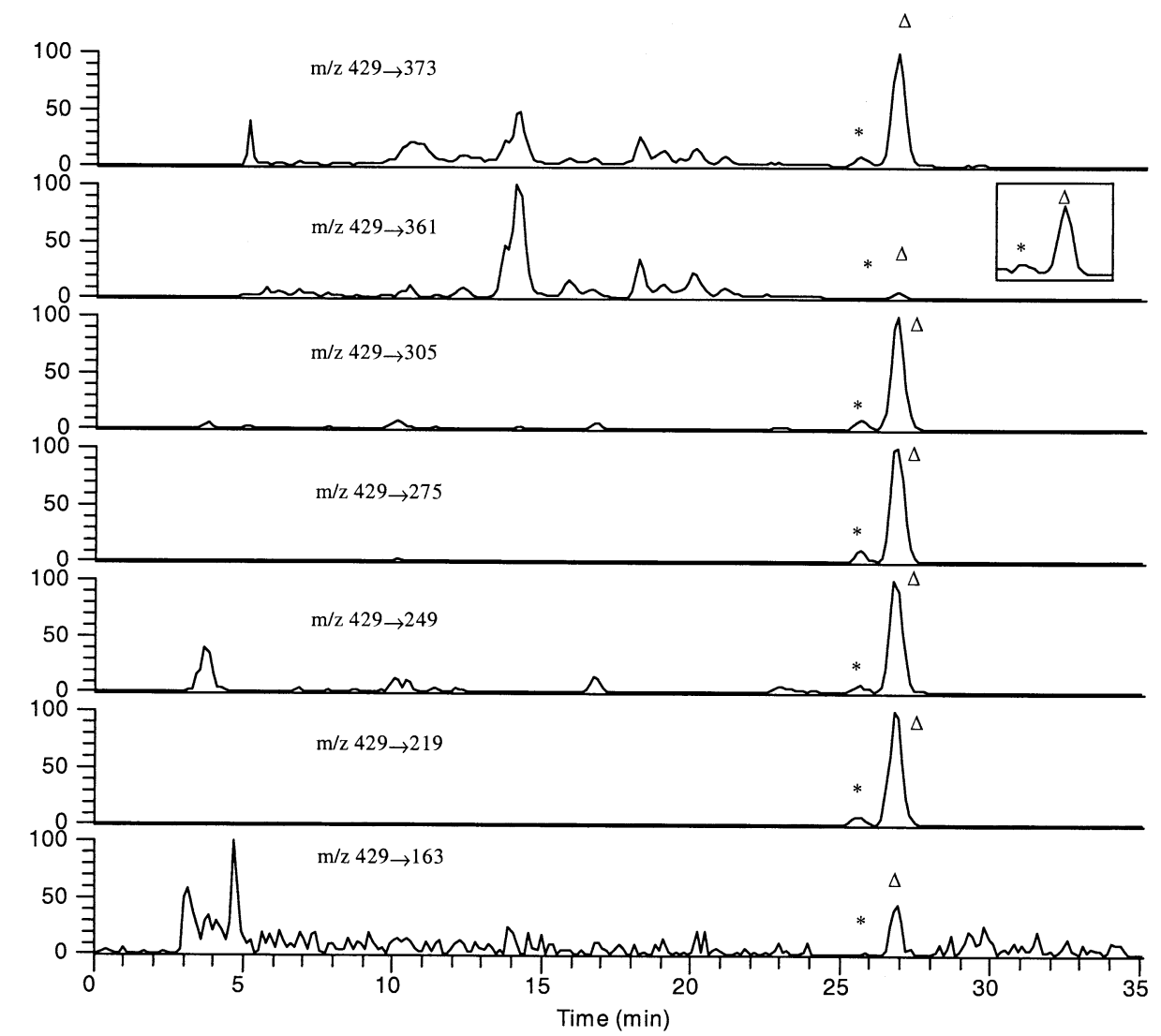

Figure 6. SRM-LC-MS/MS chromatograms of adprelupulone (asterisk) and prelupulone (open triangle).

$\left.\mathrm{H}-\mathrm{C}_{4} \mathrm{H}_{8}\right]^{+},\left[\mathrm{M}+\mathrm{H}-\mathrm{C}_{5} \mathrm{H}_{8}\right]^{+},\left[\mathrm{M}+\mathrm{H}-\mathrm{C}_{5} \mathrm{H}_{8}-\right.$ $\left.\mathrm{C}_{4} \mathrm{H}_{8}\right]^{+},\left[\mathrm{M}+\mathrm{H}-\mathrm{C}_{4} \mathrm{H}_{8}-\mathrm{C}_{5} \mathrm{H}_{8}-\mathrm{CO}^{+},[\mathrm{M}+\mathrm{H}-\right.$ $\left.\mathrm{C}_{5} \mathrm{H}_{8}-2 \mathrm{C}_{4} \mathrm{H}_{8}\right]^{+},\left[\mathrm{M}+\mathrm{H}-2 \mathrm{C}_{4} \mathrm{H}_{8}-\mathrm{C}_{5} \mathrm{H}_{8}-\mathrm{CO}\right]^{+}$and $[\mathrm{M}+$ $\left.\mathrm{H}-3 \mathrm{C}_{4} \mathrm{H}_{8}-\mathrm{C}_{5} \mathrm{H}_{8}-\mathrm{CO}\right]^{+}$, respectively. Determination of postlupulone was performed initially by monitoring the decay of protonated ion to the most intensive product ion $(387 \rightarrow 263)$. In the SRM chromatogram, several peaks presented and the authentic peak could not be differentiated from the false signals. Consequently, more experiments were necessary to detect this com-<smiles>CCCC(=O)C1=C(O)C(CC=C(C)C)=C(O)C(O)(CC=C(C)C)C1=O</smiles>

$m / 2349[M+H]^{+}$<smiles>CCCC(=O)C1=C(O)C(CC=C(C)C)=C(O)C(=CC=C(C)C)C1=O</smiles>

$m / \mathbf{z} 331\left[\mathrm{M}+\mathrm{H}-\mathrm{H}_{2} \mathrm{O}\right]^{+}$<smiles>CCCC(=O)C1=C(O)C(CC=C(C)C)=C(O)C2(O)C[O+]=C12</smiles>

$m / 2293\left[\mathrm{M}+\mathrm{H}-\mathrm{C}_{4} \mathrm{H}_{8}\right]^{+}$

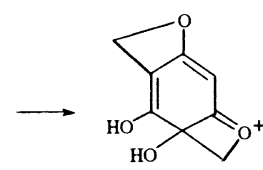

m/z $167\left[\mathrm{M}+\mathrm{H}-2 \mathrm{C}_{4} \mathrm{H}_{8}-\mathrm{C}_{3} \mathrm{H}_{6}-\mathrm{CO}^{+}\right.$

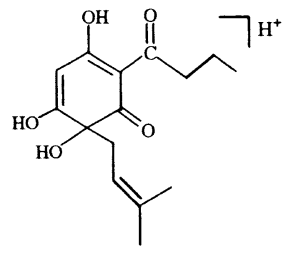

$\mathrm{m} / \mathrm{z} 281\left[\mathrm{M}+\mathrm{H}-\mathrm{C}_{5} \mathrm{H}_{8}\right]^{+}$

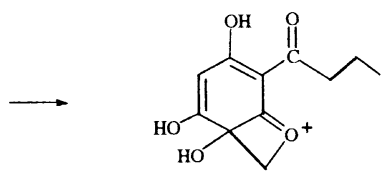

$\mathrm{m} / \mathbf{2} 225\left[\mathrm{M}+\mathrm{H}-\mathrm{C}_{5} \mathrm{H}_{8}-\mathrm{C}_{4} \mathrm{H}_{8}\right]^{+}$

Scheme 1. Proposed fragmentation pathway of cohumulone. 


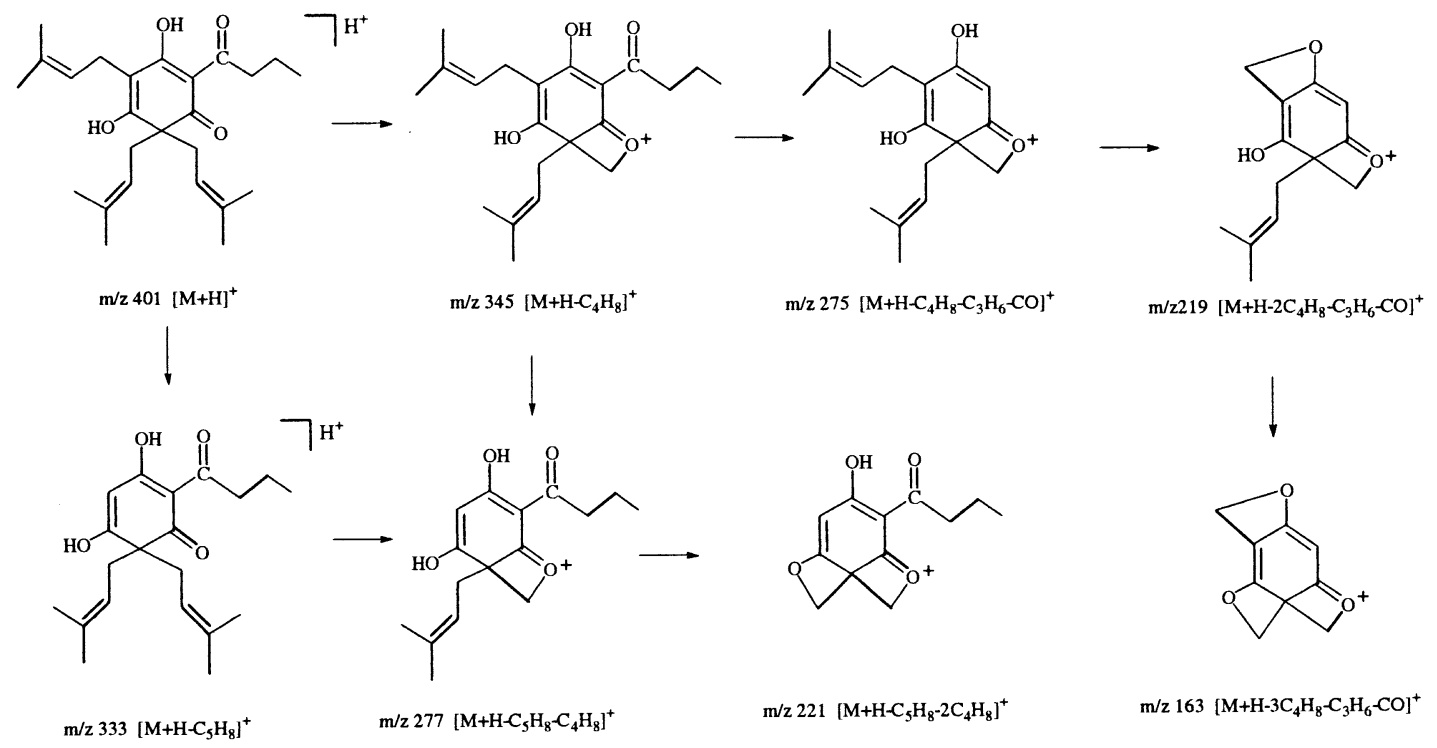

Scheme 2. Proposed fragmentation pathway of colupulone.

pound unequivocally. The scanning of seven transitions, $\mathrm{m} / \mathrm{z} 387 \rightarrow 331,319,263,207,275,219$, and 163 were carried out in one HPLC run to detect this compound. The experiment showed that there was a single peak, of which the retention time was observed at $13.57 \mathrm{~min}$, presenting in every SRM-LC/MS/MS chromatogram. The existence of postlupulone in the hop extract was ultimately confirmed by the SRM experiment.

The other minor hop acids were selectively detected by SRM in tandem MS using pair ions (each $[\mathrm{M}+\mathrm{H}]^{+}$ to its related specific product ions as predicted in Table 1 for $\alpha$-acids and in Table 2 for $\beta$-acids). If scanning of each of protonated ion-product ion transition for any bitter acid produced a positive response in the MS/MS chromatogram at the same retention time, the existence of such a targeted compound in the herb was confirmed. Discrimination between the isomers was also performed in considering their retention characteristics and relative amounts as reported $[4,10]$. Using MS/MS analysis in combination with chromatographic rule, the five minor hop acids, posthumulone, prehumulone, adprehumulone, prelupulone, and "adprelupulone", were determined with retention times at $8.54 \mathrm{~min}, 14.20$ $\mathrm{min}, 14.98 \mathrm{~min}, 25.47 \mathrm{~min}$, and $26.67 \mathrm{~min}$, respectively (Figure 5).

It is interesting that the presence of adprelupulone in hop had never been reported before, though adprehumulone, its analog, had been isolated and identified [1]. Adprelupulone may exist naturally in hop, but the isolation of such trace compound will be very difficult. In this experiment MS-MS was used to detect this compound and its presence in hop was observed for the first time by LC/MS/MS experiments (Figure 6). SRM provides as its great advantage the high selectivity and sensitivity for quantitative analysis in many fields. The use of simultaneous monitoring of the transitions of the precursor ion to a group of specific product ions made it possible to verify the HPLC peak assignments of target compounds for qualitative analysis. In this report the application was demonstrated in the qualitative identification of target minor hop acids in the complex extract and confirmatory results were acquired rapidly without tedious isolation procedures.

\section{Conclusion}

In our study we developed an isocratic separation method using acetonitrile-aqueous formic acid elution system to separate hop acids within $30 \mathrm{~min}$ in an HPLC run. The fragmentation rules were acquired by the analysis of specific structural information of the major hop acids for $\alpha$ - and $\beta$-biter acids, respectively. The minor bitter acids were thus detected in crude extract of hop by using SRM based on the MS-MS analyses of their homologs. SRM-LC/MS/MS demonstrates both better selectivity and sensitivity compared with conventional LC-UV methods and proves to be an attractive choice for identification of homologs in a complex mixture. (Schemes 1 and 2).

\section{Acknowledgments}

The authors thank Yuheng Pan for supplying herb material, Jibin Han for sample preparation, and all colleagues for their support of this study.

\section{References}

1. Smith, R. J.; Davidson, D. Natural Foam Stabilizing and Bittering Compounds Derived from Hops. J. Am. Soc. Brew. Chem. 1998, 56, 52-57.

2. Hermans-Lokkerbol, A. C. J.; Hoek, A. C.; Verpoorte, R. Preparative Separation of Bitter Acids from Hop Extracts by Centrifugal Partition Chromatography. J. Chromatogr. A 1997, $771,71-80$. 
3. Fung, S. Y.; Brussee, J.; van der Hoeven, R. A. M.; Niessen, W. M. A.; Scheffer, J. J. C.; Verpoorte, R. Analysis of Proposed Aromatic Precursors of Hop Bitter Acids. J. Nat. Prod. 1994, 57, 452-459.

4. Hermans-Lokkerbol, A. C. J.; Verpoorte, R. Development and Validation of a High Performance Liquid Chromatography System for the Analysis of Hop Bitter Acids. J. Chromatogr. A 1994, 669, 65-73.

5. Hermans-Lokkerbol, A. C. J.; Verpoorte, R. Preparative Separation and Isolation of Three $\alpha$-Bitter Acids from Hop, Нumulus lupulus L., by Centrifugal Partition Chromatography. J. Chromatogr. A 1994, 664, 45-53.

6. Hann, J. T. Fast LC Analysis of the $\alpha$-Acid Content of "Fresh" and "Aged" Hops. Chromatographia 1987, 24, 510-512.
7. Sandra, P.; Steenbeke, G.; Ghys, M. Micro Liquid Chromatography-Diode Array Detection of Hop Bitter Acids. J. High Res. Chromatogr. 1990, 13, 527-528.

8. Verzele, M.; van de Velde, N. High Performance Liquid Chromatography with Photodiode Array Detection of Minor Hop Bitter Acids in Hops Extracts and in Beer. J. Chromatogr. 1987, 387, 473-480.

9. Vindevogel, J.; Sandra, P. Micellar Eelectrokinetic Chromatography of Ionic Compounds: The Analysis of Hop Bitter Acids. J. High Res. Chromatogr. 1991, 14, 795-801.

10. Hofte, A. J. P.; van der Hoeven, R. A. M. Characterization of Hop Acids by Liquid Chromatography with Negative Electrospray Ionization Mass Spectrometry. J. Am. Soc. Brew. Chem. 1998, 56, 118-122. 